\title{
The tetragonal-monoclinic, ferroelastic transformation in yttrium tantalate and effect of zirconia alloying
}

\section{Citation}

Shian, Samuel, Pankaj Sarin, Mary Gurak, Mor Baram, Waltraud M. Kriven, and David R. Clarke. 2014. "The Tetragonal-monoclinic, Ferroelastic Transformation in Yttrium Tantalate and Effect of Zirconia Alloying." Acta Materialia 69 (May): 196-202. doi:10.1016/j.actamat.2014.01.054. http:// dx.doi.org/10.1016/j.actamat.2014.01.054.

\section{Published Version}

doi:10.1016/j.actamat.2014.01.054

\section{Permanent link}

http://nrs.harvard.edu/urn-3:HUL.InstRepos:11858826

\section{Terms of Use}

This article was downloaded from Harvard University's DASH repository, and is made available under the terms and conditions applicable to Open Access Policy Articles, as set forth at http:// nrs.harvard.edu/urn-3:HUL.InstRepos:dash.current.terms-of-use\#OAP

\section{Share Your Story}

The Harvard community has made this article openly available.

Please share how this access benefits you. Submit a story.

Accessibility 


\section{THE TETRAGONAL-MONOCLINIC, FERROELASTIC TRANSFORMATION IN YTTRIUM TANTALATE AND EFFECT OF ZIRCONIA ALLOYING}

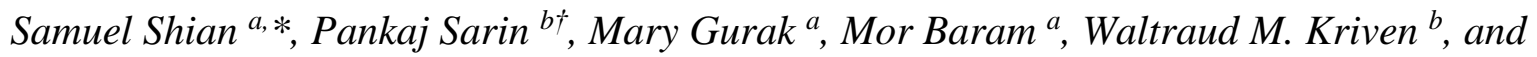
David R. Clarke ${ }^{a}$

${ }^{a}$ School of Engineering and Applied Sciences, Harvard University, Cambridge, MA 02138, USA ${ }^{\mathrm{b}}$ Department of Materials Science and Engineering, University of Illinois at Urbana Champaign, Urbana, IL 61801, USA.

$\dagger$ Present address: School of Materials Science and Engineering, Oklahoma State University, Tulsa, OK 74106, USA

*Corresponding author Tel.: +1 617496 4295;

E-mail address: sshian@seas.harvard.edu (S. Shian)

Keywords: ferroelastic; phase transformation; yttrium tantalate; in-situ XRD; thermal barrier coatings;

Oxide compositions of equimolar $\mathrm{YO}_{1.5}$ and $\mathrm{TaO}_{2.5}$ in the $\mathrm{Y}-\mathrm{Ta}-\mathrm{Zr}-\mathrm{O}$ system have attractive properties for high temperature applications including as thermal barrier coatings. The effect of zirconia concentration, from 0 to 20 mole percent cation, on the tetragonal to monoclinic phase transition has been studied using high temperature X-ray diffraction, Raman spectroscopy, and electron microscopy. The transformation is reversible and the temperature variation of an order parameter based on the spontaneous strain is consistent with the transformation being ferroelastic, a critical feature for toughening at high temperatures. The presence of twin domains further supports this conclusion. Additionally, stabilization of the tetragonal phase with increasing $\mathrm{ZrO}_{2}$ is evident from the amount of partially retained tetragonal phase at room temperature. 


\section{Introduction}

Integral to the development of high-performance, energy-efficient next generation turbine engines is the quest for oxide materials that can be used as higher temperature, thermal barrier coatings than current yttria-stabilized zirconia $(7 \mathrm{YSZ}) .{ }^{[1]}$ These materials are required to have not only low thermal conductivity but also match the high-temperature toughening, ferroelastic toughening exhibited by 7YSZ. As part of this search, the zirconia-rich portion of the $\mathrm{Y}-\mathrm{Ta}-\mathrm{Zr}-\mathrm{O}$ system has been investigated. The basic features of the zirconia-rich portion of the phase diagram were described by Kim and Tien, ${ }^{[2]}$ with an emphasis on the stability of the tetragonal and cubic phases. More recently, in a series of papers, Levi and colleagues have elaborated on the phase stabilities in the zirconia-rich portion of the phase diagram, more clearly delineating the phase fields and relating some of the physical properties such as fracture toughness and thermal conductivity to the phase content. ${ }^{[3,4]}$ They have also explicitly considered the opportunities for phases in this system as prospective thermal barrier coatings. ${ }^{[5]}$ Much less is known about the phase fields in the vicinity of $\mathrm{YTaO}_{4}$ and reference to the phase diagram compilations of the American Ceramic Society ${ }^{[6]}$ indicates that along the $\mathrm{Y}_{2} \mathrm{O}_{3}-\mathrm{Ta}_{2} \mathrm{O}_{5}$ join there are two other phases, $\mathrm{YTa}_{3} \mathrm{O}_{9}$ and $\mathrm{Y}_{3} \mathrm{TaO}_{7}$, in addition to $\mathrm{YTaO}_{4}$. No solubility of zirconia in $\mathrm{YTaO}_{4}$ is indicated in the published phase diagram but preliminary work by Levi and Clarke has indicated that there is some limited solubility of zirconia along the $\mathrm{YTaO}_{4}-\mathrm{ZrO}_{2}$ line, similar to the line extending from pure $\mathrm{ZrO}_{2}$ with equal co-substitution of $\mathrm{Y}$ and $\mathrm{Ta}$ for $\mathrm{Zr}$ while maintaining overall charge neutrality. These preliminary studies indicate that the compound is a line compound, $\mathrm{Y}_{1-\mathrm{x}} \mathrm{Ta}_{1-\mathrm{x}} \mathrm{Zr}_{2 \mathrm{x}} \mathrm{O}_{4}$, with little solubility for either excess $\mathrm{Ta}^{5+}$ or $\mathrm{Y}^{3+}$. Any excess is accommodated by a second phase, either $\mathrm{YTa}_{3} \mathrm{O}_{9}$ or $\mathrm{Y}_{3} \mathrm{TaO}_{7}$. Based on the diagram by Kim and 
Tien, ${ }^{[2]}$ and the more recent work of Pitek and Levi, ${ }^{[5]}$ the tentative phase diagram at $1500^{\circ} \mathrm{C}$ that has guided our studies is shown in Fig. 1.

The isothermal ternary phase diagram, however, is lacking information about the stability of $\mathrm{YTaO}_{4}$ and its transformation as a function of temperature. The existence of a very hightemperature phase transformation in $\mathrm{YTaO}_{4}$ was reported in the Russian literature by Komkov ${ }^{[7]}$ and subsequently studied by Wolten and Chase ${ }^{[8]}$ as well as by Stubican. ${ }^{[9]}$ The work at the time identified and clarified the existence of two monoclinic phases, termed $m$ and $m,{ }^{[8,10]}$ and the space groups of both were tabulated. Unfortunately, interest in this transformation languished, perhaps, in part, because of the discovery of transformation toughening in zirconia partiallystabilized with calcia in CSIRO, Australia ${ }^{[1]}$ and the tremendous excitement it spurred in the ceramics community.

The purpose of this work was to study the effect of $\mathrm{ZrO}_{2}$ alloying on the $t-m$ transformation in $\mathrm{YTaO}_{4}$ and microstructural evidence for ferroelasticity. Structural characterizations and calculation of the spontaneous strain based on crystal symmetry indicate that the transformation remains displacive even for substantial zirconia concentrations. We show that alloying with zirconia does not affect the $t-m$ transformation other than to reduce the transformation temperature and that the lattice parameters evolve continuously through the transformation. Additionally, the transformation is accompanied by the formation of twin domains, a characteristic of a ferroelastic transformation.

\section{Experimental Details}

The materials studied in this work were in the form of both powders and pellets. Five compositions of equimolar of $\mathrm{Y}^{3+}$ and $\mathrm{Ta}^{5+}$ with varying contents of $\mathrm{Zr}^{4+},(0,5,10,15$, and 20 
cation mole percentage $(\mathrm{mol} \%)$ were prepared. The powders were synthesized by the reverse coprecipitation method using zirconium oxynitrate hydrate (>99\%), yttrium nitrate hexahydrate (>99.8\%) and tantalum chloride (99.99\%) precursor solutions (all chemicals used in this experiment were purchased from Sigma-Aldrich). Solutions of $\mathrm{ZrO}\left(\mathrm{NO}_{2}\right)_{2}$ and $\mathrm{Y}\left(\mathrm{NO}_{3}\right)_{3}$ in deionized (DI) water and solutions of $\mathrm{TaCl}_{5}$ in ethanol were first prepared and calibrated using gravimetric method. Properly calculated proportions of the solutions were then mixed together just before the precipitation step to prevent the hydrolysis of the $\mathrm{TaCl}_{5}$ in water. Once mixed, precipitation was initiated by slowly adding the solution, dropwise, into ammonium hydroxide solution (the $\mathrm{pH}$ value was controlled to be $>10$ during precipitation) with vigorous stirring. The precipitates were isolated by centrifugation and washed twice, first with DI water and then with ethanol, and dried over night at $70^{\circ} \mathrm{C}$. The precipitates were then calcined at $700^{\circ} \mathrm{C}$ for $2 \mathrm{~h}$ to remove the organic constituent, producing molecularly mixed metal oxides. The resultant powders were ground with a mortar and pestle and passed through a $<325$ mesh sieve. Solid disk pellets were then made by cold, uniaxial pressing the sieved powder at $100 \mathrm{MPa}$ and then sintering for $5 \mathrm{~h}$ at $1500^{\circ} \mathrm{C}$ at a ramp rate of $8^{\circ} \mathrm{C} / \mathrm{min}$. Raman spectra on the pellets were recorded using LabRAM Aramis Raman system (Horiba Jobin Yvon, Edison, NJ) with laser excitation at $532 \mathrm{~nm}$. Transmission electron microscopy (TEM) sample was prepared using a dual beam, focused ion beam (FIB) and scanning electron microscopy (FIB-SEM, Zeiss NVision 40) utilizing the lift-out method. To remove the damages caused by Ga ion during FIB, the sample was cleaned using the Fischione NanoMill 1040. The microstructure was then observed using a JEOL 2100 TEM.

High temperature X-ray diffraction studies were performed with a quadrupole lamp furnace at the National Synchrotron Light Source in Brookhaven National Laboratory.[12] 
Whole pattern fitting and Rietveld analysis of the acquired high temperature X-ray data was conducted using Jade software (Materials Data Incorporated, Livermore, CA). The crystal structures of the $m$ - and $t$-phases were based on structure No. 109190 and 37138 , reported in the Inorganic Crystal Structure Database (ICSD v. 2011/1, National Institute of Standards and Technology, Gaithersburg, MD; Fachinformationszentrum (FIZ), Karlsruhe, Germany).

\section{Results}

As has been described elsewhere [13] for $\mathrm{YTaO}_{4}$, an initially amorphous powder first transformed to the m' phase and then with further heating transformed to a tetragonal phase. This same sequence was observed in the zirconia-alloyed materials as well. In this study, X-ray diffraction measurements were conducted on powders that had already been heated to $1600^{\circ} \mathrm{C}$. X-ray diffraction patterns were acquired while heating the powders from room temperature to $1600^{\circ} \mathrm{C}$ and then cooling back to room temperature. The X-ray reflections for the starting phase could be indexed as a monoclinic phase, and in the case of the pure $\mathrm{YTaO}_{4}$ corresponded to those previously reported in Powder Diffraction File number 24-1415 [14]. The detailed crystallography of the transformation in pure $\mathrm{YTaO}_{4}$ will be described in a forthcoming publication [15]. A systematic peak broadening was observed with increasing $\mathrm{ZrO}_{2}$ concentration, indicating a decrease in crystallite size. This is consistent with SEM observation showing the grain size to monotonically decrease as the $\mathrm{ZrO}_{2}$ concentration increases. In addition to the systematic shifts in the peaks as a result of the thermal expansion and contraction of the phases during heating and cooling, respectively, there was a reversible phase transformation between the monoclinic and tetragonal phases. For the 10 to $20 \mathrm{~mol} \%$ zirconia samples, some tetragonal phase was retained during cooling to room temperature, as shown in 
Fig. 3(a). The composition with $5 \mathrm{~mol} \%$ zirconia may also have retained tetragonal phase at room temperature, however, because of peaks overlap between the tetragonal and monoclinic phases, the tetragonal reflections may have been masked by the more intense monoclinic peaks.

The unit cell parameters as a function of temperature for all the compositions were derived from the X-ray patterns using Rietveld analysis. The refined unit cell parameters and volume of two compositions, pure $\mathrm{YTaO}_{4}$ and the material containing $20 \mathrm{~mol} \% \mathrm{ZrO}_{2}$, are shown in Fig. 2(a)-(c). The latter includes the lattice parameters of the retained tetragonal phase on cooling to room temperature. The variation in the monoclinic angle, $\beta$, with temperature for the different zirconia concentrations is shown in Fig. 2(d). All the data could be fitted with a scaling relation in which the reduced monoclinic angle, $\Delta \beta=\beta-90$, varied as a power law of a normalized temperature:

$$
\frac{\Delta \beta}{\Delta \beta_{o}}=\left(1-\frac{T}{T_{t r}}\right)^{n}, \quad \text { for } T<T_{t r}
$$

where $\Delta \beta_{o}=\beta_{o}-90, \beta_{o}$ is the extrapolated monoclinic angle at $0 \mathrm{~K}, T_{t r}$ is the transformation temperature, and $\mathrm{n}$ is an exponent. The values of the parameters were determined by simultaneously fitting all the data. The monoclinic angles for all compositions were found to fit the above equation at $n=0.34 \pm 0.02$, which are shown as solid lines in Fig. 2(d). The intercept of these extrapolated fitting lines with the temperature-axis, gave the transformation temperature, which is shown in Fig. 3(a). Furthermore, the monoclinic angle, measured at room temperature, decreased with increasing zirconia content, as shown in Fig. 3(b).

Raman spectra were recorded from each of the pellet samples of differing zirconia contents after heating to a temperature of $1600^{\circ} \mathrm{C}$, as shown in Fig. 4. Strikingly, the spectra are, apart from slight peak shifts, indistinguishable from one another despite the varying concentration of zirconia in the materials. All the peaks could be indexed as monoclinic with the 
same Raman shifts and number of peaks as reported for the monoclinic phase of pure $\mathrm{YTaO}_{4}$ by Nazarov [16]. With increasing zirconia contents, significant line broadening is evident, especially for the external lines, however individual lines were still distinct.

\section{Discussion}

Our results raise several intriguing and fundamental questions. For instance, does zirconia alloying affect the nature of the transformation? Why is the transformation, other than its temperature, unaffected by zirconia alloying despite the presence of $\mathrm{Zr}^{4+}$ in the crystal structures? And, why does zirconia exhibit such a large solubility in $\mathrm{YTaO}_{4}$ despite having a tetravalent charge?

Qualitatively, our observations are consistent with the transformation mechanism remaining displacive as zirconia is alloyed into the $\mathrm{YTaO}_{4}$. For instance, the unit cell volume changed continuously with temperature whereas the coefficient of thermal expansion changed discontinuously with temperature as illustrated in Fig. 2(c). In addition, there was the appearance of twins in the monoclinic phase and surface relief in all the samples on cooling from above the $m-t$ transformation temperature. These can be seen in both the SEM and TEM images shown in Fig. 6. In particular, the HRTEM image showed twin variants [17] with twin boundaries between planes ( $20-9.1)$ and $\left(9.102\right.$ ) and a twin angle of $99.05^{\circ}$ (Fig. 6(c)). Details of the TEM image analysis and ferroelastic transformation mechanism will be published elsewhere [18].

More exacting was the characterization of the crystallography of the transformation. The most notable comparison is with the studies of the structurally related rare-earth niobates [19, 20]. These studies analyzed the evolution of the spontaneous strain as a function of temperature to demonstrate that the monoclinic-to-tetragonal phase transformation is second order. 
Introduced by Aizu to quantify the extent of ferroelasticity [21], the analysis of spontaneous strain compares lattice strain components for all possible orientations of the transformed phase to those of the parent phase. The parent phase is assumed to have zero spontaneous strain over the whole temperature range. For the tetragonal to monoclinic transformations in $\mathrm{YTaO}_{4}$, the ferroelastic operator $\mathbf{F}$ is a rotation matrix of $90^{\circ}$ around $\mathbf{z}$ axis of tetragonal, and the strain components can be expressed in terms of the unit cell parameters as [22] :

$$
\begin{aligned}
& e_{11}=\frac{c_{m} \sin \beta_{m}^{*}}{a_{t}}-1 \\
& e_{22}=\frac{a_{m}}{b_{t}}-1 \\
& e_{33}=\frac{b_{m}}{c_{t}}-1 \\
& e_{12}=e_{21}=-\frac{1}{2}\left[\frac{c_{m} \cos \beta_{m}^{*}}{a_{t}}\right] \\
& e_{13}=e_{31}=e_{23}=e_{32}=0
\end{aligned}
$$

There are two possible orientation states, $S_{1}$ and $S_{2}$, in monoclinic system [21] and the resulting strain tensors are expressed by

$$
\begin{aligned}
& \varepsilon_{i j}^{s}\left(S_{1}\right)=\left(\begin{array}{ccc}
-\varepsilon_{11}^{s} & \varepsilon_{12}^{s} & 0 \\
\varepsilon_{12}^{s} & \varepsilon_{11}^{s} & 0 \\
0 & 0 & 0
\end{array}\right) \\
& \varepsilon_{i j}^{s}\left(S_{2}\right)=-\varepsilon_{i j}^{s}\left(S_{1}\right)
\end{aligned}
$$

where $\varepsilon_{11}^{s}=1 / 2\left(e_{11}-e_{22}\right)$ and $\varepsilon_{12}^{s}=e_{12}$. The magnitude of spontaneous strain, $\left(\varepsilon_{\mathrm{s}}\right)^{2}$, is then:

$$
\left.\left(\varepsilon^{s}\right)^{2}=2\left[\left(\varepsilon_{i j}^{S}\left(S_{1}\right)\right)^{2}+\left(\varepsilon_{i j}^{S}\left(S_{2}\right)\right)^{2}\right)\right]
$$

The spontaneous strain for each zirconia concentration, normalized by the extrapolated spontaneous strain at $0 \mathrm{~K}, \varepsilon_{0}^{s}$, was found to have the same functional dependence on temperature as is characteristic of order parameter variations of mean-field phase transitions[23], 


$$
\frac{\varepsilon^{s}}{\varepsilon_{o}^{s}}=\left(1-\frac{T}{T_{t r}}\right)^{n} \quad, \quad \text { for } T<T_{t r}
$$

The fitting is shown in Fig. 5(b). As can be seen, all the data for the different zirconia contents falls on a line with $n=0.34 \pm 0.02$. Note that the right hand side of equation (1) and (5) are identical in form. Since the fitted exponent in equation (1) and (5) are the same, plotting the normalized monoclinic angle as a function of reduced temperature should result in a similar curve. Indeed, this is so as is shown in Fig. 5(a). While we cannot provide a justification for the value of the exponent in the power law description of the common curve, the fact that the curve described the data for the entire range of compositions strongly implies that the nature of the transformation was not affected by alloying $\mathrm{YTaO}_{4}$ with zirconia. We also note that although the exponent $n=0.34 \pm 0.02$ fits the data over a wide temperature range, close to the transformation temperatures, the mean field exponent of $n=0.5$ fits equally well.

Based on our observations, there are two compelling reasons to conclude that the $\mathrm{Zr}^{4+}$ ion substituted equally for both the $\mathrm{Y}^{3+}$ and $\mathrm{Ta}^{5+}$ ions in the monoclinic and tetragonal structures. The first was that the crystal symmetries obtained from Rietveld analysis of the X-ray data for the tetragonal and monoclinic phases were unchanged with zirconia alloying. The second was that the Raman spectra of the monoclinic phase were also unchanged, other than small broadening of each line, with increasing zirconia content. Since the Raman spectrum is sensitive to structural symmetries at a smaller length scale than X-ray diffraction and is also more sensitive to displacements of the lighter oxygen ions than the cations, the unchanged Raman spectrum confirmed that the local symmetries were also unchanged. Furthermore, the individual Raman lines remained distinguishable from one another and did not merge into one another with increasing zirconia, unlike the case where $\mathrm{Y}$ and $\mathrm{Ta}$ are co-substituted for $\mathrm{ZrO}_{2},{ }^{[3]}$ indicating that there was little local distortion or clustering. 
From a crystal chemistry classification, the monoclinic form of $\mathrm{YTaO}_{4}$, is iso-structural with the monoclinic form of the mineral fergusonite (impure $\mathrm{YNbO}_{4}$ ) and has a nominal formula $\mathrm{Y}^{3+} \mathrm{Ta}^{5+} \mathrm{O}_{4}{ }^{2-}$ where various trivalent rare-earth ions can occupy the $\mathrm{Y}^{3+}$ site and $\mathrm{Nb}^{5+}$ can substitute in whole or part for the $\mathrm{Ta}^{5+}$. The tetragonal form of the mineral is a distorted version of the scheelite structure $\left(\mathrm{CaWO}_{4}\right)$. In both the tetragonal and monoclinic structures the trivalent rare-earth ions have an 8-fold coordination in a deformed polyhedron and the pentavalent ions,

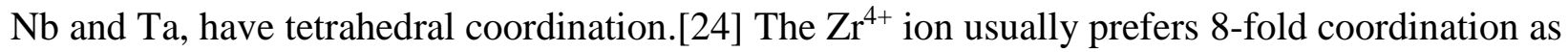
it does in cubic and tetragonal zirconia[25] but it can also adopts a 7-fold coordination as it does in monoclinic zirconia,[26] for instance. It is not reported to adopt a tetrahedral coordination so it is not obvious why zirconia exhibits such an extensive solubility in either the tetragonal or monoclinic phases that we have been studying. It is unlikely that the structure can accommodate vacancies unless there were an equal number of cation and anion vacancies, since there was no evidence for non-stoichiometry. Furthermore, it is difficult to contemplate the structure being stable, let alone maintaining the same space group as pure $\mathrm{YTaO}_{4}$ with $20 \%$ of the atomic sites occupied by vacancies. Consequently, it is likely that $\mathrm{Zr}$ ions substitute in pairs for both $\mathrm{Y}$ and Ta ions within a unit cell. The ionic radii of $\mathrm{Y}^{3+}, \mathrm{Zr}^{4+}$ and $\mathrm{Ta}^{5+}$ are reported to be $0.1019,0.084$ and $0.074 \mathrm{~nm}$, respectively.[25] Since the average of the ionic radii of $\mathrm{Y}^{3+}$ and $\mathrm{Ta}^{5+}$ is $0.087 \mathrm{~nm}$ and differs by only $3.5 \%$ from that of the $\mathrm{Zr}^{4+}$ ion, the substitution of both $\mathrm{Y}^{3+}$ and $\mathrm{Ta}^{5+}$ sites by a pair of $\mathrm{Zr}^{4+}$ ions was expected to slightly distort the crystal structure of the parent phase. Nevertheless, such distortion was evident from the broadening in Raman peaks as the $\mathrm{Zr}$ ions concentration increased, indicating a decline in local structural symmetries. Additionally, the unit cell volume decreased, as shown in Fig. 2, as $\mathrm{Zr}^{4+}$ ions replaced the $\mathrm{Y}^{3+}$ and $\mathrm{Ta}^{5+}$ ions, consistent 
with the substitution of pairs of $\mathrm{Zr}^{4+}$ ions. However, the tetragonality, given by the ratio of c/a for the high temperature tetragonal phase, not shown, decreased with increasing $\mathrm{Zr}^{4+}$ concentration.

The demonstration that $\mathrm{YTaO}_{4}$ alloyed with zirconia exhibits a displacive, possibly ferroelastic tetragonal-monoclinic transformation inevitably suggests a comparison with the transformation in yttria-stabilized zirconia that is the basis for transformation toughening.[27] In both systems, the unit cell volume of the monoclinic phase is larger than the tetragonal unit cell, and the two structures are related by a lattice shear. The volume change and the shear strain are both smaller in the zirconia alloyed $\mathrm{YTaO}_{4}$ system than that in the $\mathrm{YSZ}$ system, where they are $5 \%$ and 0.15 , respectively. The room temperature monoclinic angle in YSZ is $98.91^{\circ}$. As the magnitude of transformation toughening is proportional to the volume change [28, 29] it might be expected that the toughening would be smaller. However, in many cases the volume change in YSZ is too large because of the transformation also causes microcracking so the full extent of transformation toughening can rarely be exploited. Consequently, it is possible that transformation to the monoclinic phase without microcracking may be possible. More interesting for toughening at high-temperatures, however, is the possibility of ferroelastic toughening [30] since this mechanism can operate at all temperatures, even at high temperatures. Ferroelastic toughening of metastable 7YSZ coatings has been demonstrated and is believed to be responsible for the unusual toughness of the 7YSZ coatings.[31] The attainable ferroelastic toughening is proportional to both the tetragonality and the coercive stress [31] so while the tetragonality decreases with increasing zirconia content it remains to be determined how the coercive stress varies and hence the attainable toughness.

The last similarity between the two material systems is that the tetragonal phase can be retained at temperatures down to room temperature. In the YSZ system this can occur in nano- 
sized particles $[32,33]$ as well as a metastable phase by quenching as occurs in the EB-PVD or plasma spray processes. In the $\mathrm{Y}_{1-\mathrm{x}} \mathrm{Ta}_{1-\mathrm{x}} \mathrm{Zr}_{2 \mathrm{x}} \mathrm{O}_{4}$ system, although we have evidence that the tetragonal phase can be retained, we do not yet know the conditions for its retention. It is clear, however, based on comparing the lattice parameters, that it is not the same metastable tetragonal t' phase found by Mather and Davies formed on heating from the amorphous phase before the monoclinic m' phase forms.[13]

\section{Closing Remarks}

The reversible phase transformation between a low temperature monoclinic phase and a high temperature tetragonal phase in $\mathrm{YTaO}_{4}$ is preserved despite alloying with zirconia up to concentrations of at least $20 \mathrm{~mol} \% \mathrm{ZrO}_{2}$. Both the normalized spontaneous strain and normalized monoclinic angle of all the compositions followed the same power law with respect to the reduced temperature with exponent of $0.34 \pm 0.02$. The principal effect of zirconia alloying was to decrease the transformation temperature. The decrease was, within experimental uncertainties, a linear function of zirconia concentration, from $1426 \pm 7{ }^{\circ} \mathrm{C}$ for pure $\mathrm{YTaO}_{4}$ decreasing to $821 \pm$ $47^{\circ} \mathrm{C}$ for $20 \mathrm{~mol} \%$ zirconia. Additionally, zirconia had the effect of partially stabilizing the tetragonal phase below the transformation temperature, down to room temperature, where the amount of retained tetragonal phase increased as the percentage of zirconia increased. Subsequent papers in preparation will describe the variation in thermal conductivity and fracture toughness with zirconia concentration.

One of the conclusions of this work is that the transformation is displacive and is consistent with the crystallography of a ferroelastic transformation. However, the stress-induced 
transformation and the domain switching, both hallmarks of a ferroelastic transformation [34] have still to be demonstrated. This will be a focus of future work.

\section{Acknowledgements}

This work was supported at Harvard University by a grant from ONR (N00014-012-1-0993) and at the University of Illinois by the US Air Force Office of Scientific Research (FA9550-06-10386) is gratefully acknowledged. Use of the National Synchrotron Light Source, Brookhaven

National Laboratory, is supported by the US Department of Energy, Office of Science, Office of Basic Energy Sciences, under contract No. DE-AC02-98CH10886.

\section{References}

[1] Clarke DR, Oechsner M, Padture NP. Materials Research Bulletin 2012;37:891.

[2] Kim D-J, Tien TY. Journal of the American Ceramic Society 1991;74:3061.

[3] Shen Y, Clarke DR. J Am Ceram Soc 2010;93:2024.

[4] Shen Y, Leckie RM, Levi CG, Clarke DR. Acta Materialia 2010;58:4424.

[5] Pitek FM, Levi CG. Surface and Coatings Technology 2007;201:6044.

[6] American Ceramic Society-NIST, "Phase Equilibria Diagrams", Available in electronic form from the American Ceramic Society.

[7] Komkov Al. Kristallografiya (USSR) 1959;4:836.

[8] Wolten GM, Chase AB. The American Mineralogist 1967;52:1536.

[9] Stubican VS. Journal of the American Ceramic Society 1964;47:55.

[10] Wolten GM. Acta Crystallographica 1967;23:939.

[11] Garvie RC, Hannink RHJ, Pascoe RT. Nature 1975;258:703.

[12] Sarin P, Yoon W, Jurkschat K, Zschack P, Kriven WM. Review of Scientific Instruments 2006;77:093906.

[13] Mather SA, Davies PK. Journal of the American Ceramic Society 1995;78:2737. 
[14] ICDD PDF-2. Newton Square, PA: International Center for Diffraction Data, 2003.

[15] Sarin P, Kriven W. Crystallography of the $\mathrm{YTaO}_{4}$ Phase Transformation. In preparation.

[16] Nazarov M. Moldavian Journal of the Physical Sciences 2010;9:5.

[17] Tsunekawa S, Takei H. Physica Status Solidi (a) 1978;695:695.

[18] Feng J. Ab Initio Calculations and Structural Characterization of the Ferroelastic Phase Transition in Yttrium Tantalate. In preparation.

[19] Jian L, Wayman CM. Journal of the American Ceramic Society 1997;80:803.

[20] Sarin P, Siah LF, Kriven WM. Phase Transformations in Rare Earth Niobates. In: Howe JM, Laughlin DE, Lee JK, Sorolovitz DJ, Dahmen U, editors. Solid-Solid Phase Transformations in Inorganic Materials: TMS Society, 2006. p.1023.

[21] Aizu K. J. Phys. Soc. Jpn 1970;28:706.

[22] Schlenker JL, Gibbs GV, Boisen MB. Acta Crystallographica 1978;A34:52.

[23] Yeomans JM. Statistical Mechanics of Phase Transitions. USA: Oxford University Press, 1992.

[24] Brixner LH, Chen HY. Journal of The Electrochemical Society 1983;130:2435.

[25] Shannon RD. Acta Crystallographica 1976;A32:751.

[26] Green DJ, Hannink RHJ, Swain MV. Transformation Toughening of Ceramics. Bocca Raton: CRC Press, 1989.

[27] Chevalier J, Gremillard L, Virkar AV, Clarke DR. Journal of the American Ceramic Society 2009;92:1901.

[28] McMeeking RM, Evans AG. Journal of the American Ceramic Society 1982;65:242.

[29] Chen I-W. Journal of the American Ceramic Society 1991;74:2564.

[30] Virkar AV, Matsumoto RLK. Journal of the American Ceramic Society 1986;69 C224.

[31] Mercer C, Williams JR, Clarke DR, Evans AG. Proceedings of the Royal Society of London A 2007;463:1393.

[32] Garvie RC. Journal of the Physics and Chemistry of Solids 1978;82:218.

[33] Pitcher MW, Ushakov SV, Navrotsky A, Woodfield BF, Li G, Boerio-Goates J, Tissue BM. Journal of the American Ceramic Society 2005;88:160. 
[34] Salje EKH, editor Phase Transitions in Ferroelastic and Co-Elastic Crystals. Cambridge: Cambridge University Press, 1993. 


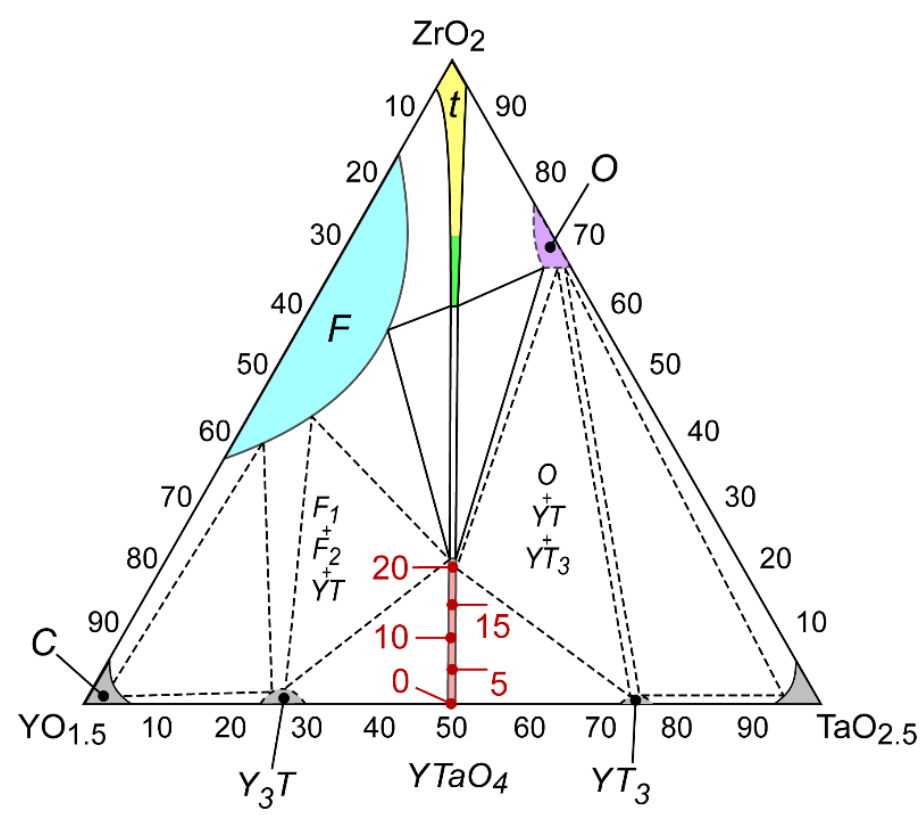

Fig. 1. Phase diagram of $\mathrm{Y}_{2} \mathrm{O}_{3}-\mathrm{ZrO}_{2}-\mathrm{Ta}_{2} \mathrm{O}_{5}$ at $1550^{\circ} \mathrm{C}$ based on the work of Kim and Tien ${ }^{[2]}$, and Pitek and Levi ${ }^{[5]}$. The dashed lines indicate tentative tie-lines based on the presumed extent of solid solution for the phases labeled. Compositions of interest in this work, $\mathrm{Y}_{1-\mathrm{x}} \mathrm{Ta}_{1-\mathrm{x}} \mathrm{Zr}_{2 \mathrm{x}} \mathrm{O}_{4}$, extend from $\mathrm{YTaO}_{4}$ towards $\mathrm{ZrO}_{2}$, as shown by $x$ or mol\% equal to $0,5,10,15$, and 20 . Note: $\mathrm{C}=$ Cubic, $\mathrm{F}=$ Fluorite, $\mathrm{O}=$ Orthorhombic, $\mathrm{t}=$ tetragonal, $\mathrm{YT}=\mathrm{YTaO}_{4}, \mathrm{Y}_{3} \mathrm{~T}=\mathrm{Y}_{3} \mathrm{TaO}_{7}, \mathrm{YT}_{3}=\mathrm{YTa}_{3} \mathrm{O}_{9}$ 

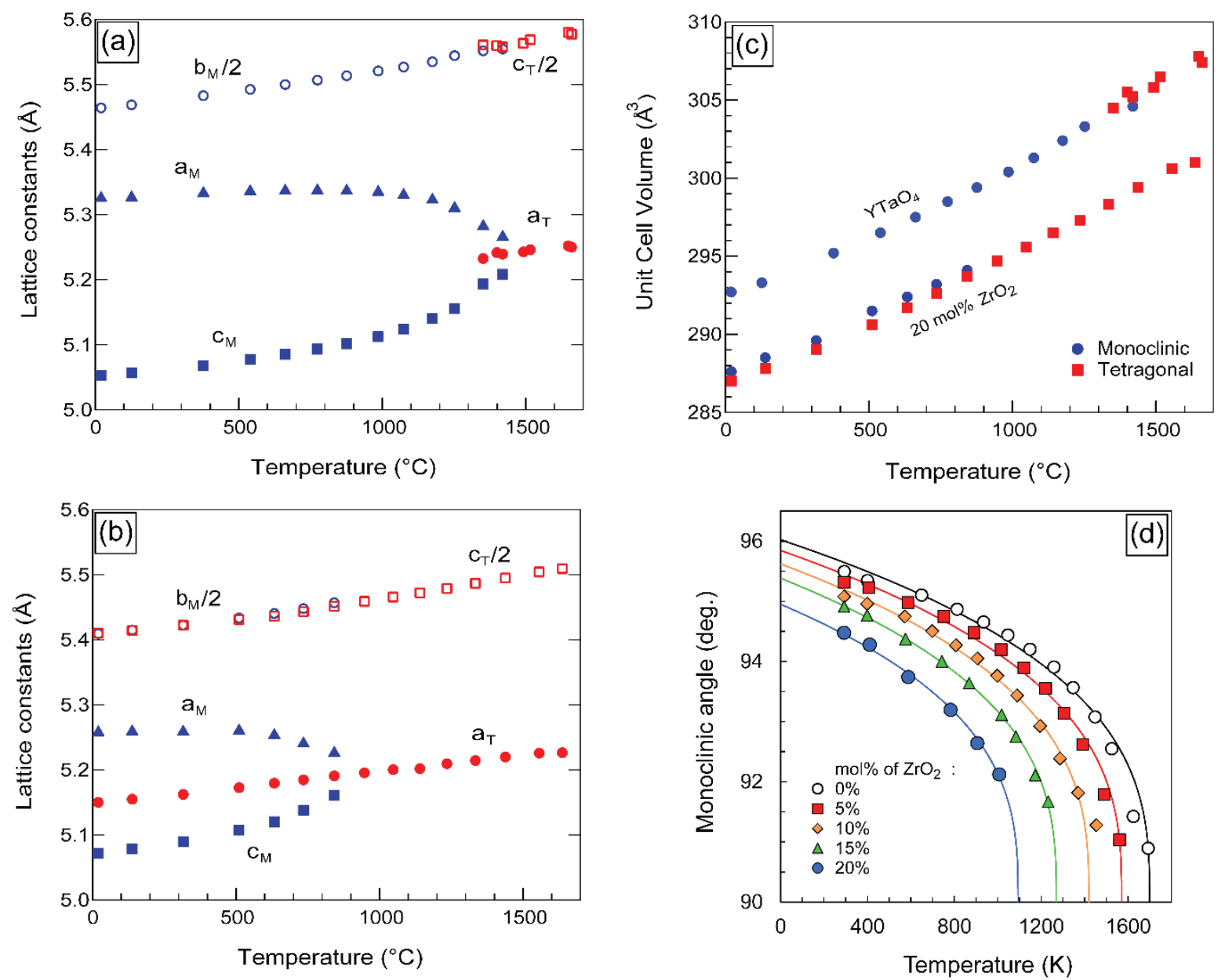

Fig. 2. Unit cell parameters as a function of temperature for (a) $\mathrm{YTaO}_{4}$ and for (b) $\mathrm{YTaO}_{4}-20$ mol\% $\mathrm{ZrO}_{2}$. Variations in unit cell volumes with temperature for the two compositions are shown in (c). (d) Variation in the monoclinic included angle, $\beta$, as a function of temperature for the different zirconia concentrations indicated. The lines shown correspond to the best fit to the data. The error bars are smaller than the symbol size. 

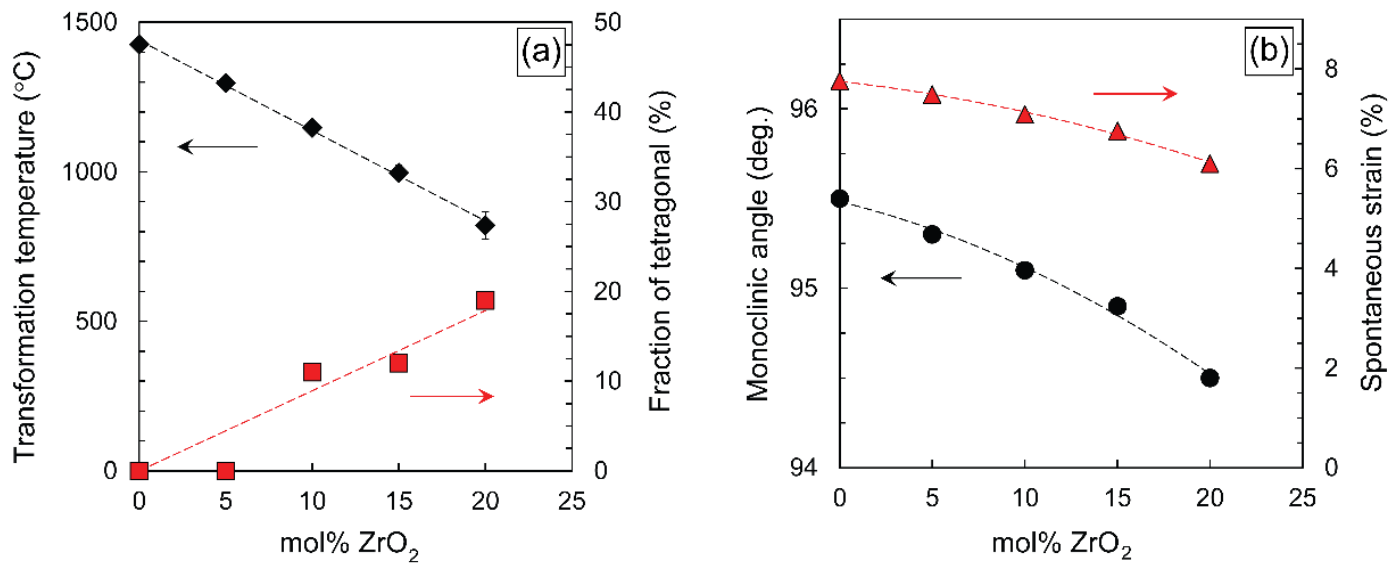

Fig. 3. (a) The transformation temperature of tetragonal to monoclinic in $\mathrm{YTaO}_{4}$ as a function of zirconia concentration. Also shown is an estimate of the percentage of tetragonal retained at room temperature. (b) The variation in the room temperature value of the monoclinic angle with zirconia concentration. Also shown is the calculated spontaneous strain with zirconia concentration at room temperature. The error bars are smaller than the symbol size unless they are specifically indicated.

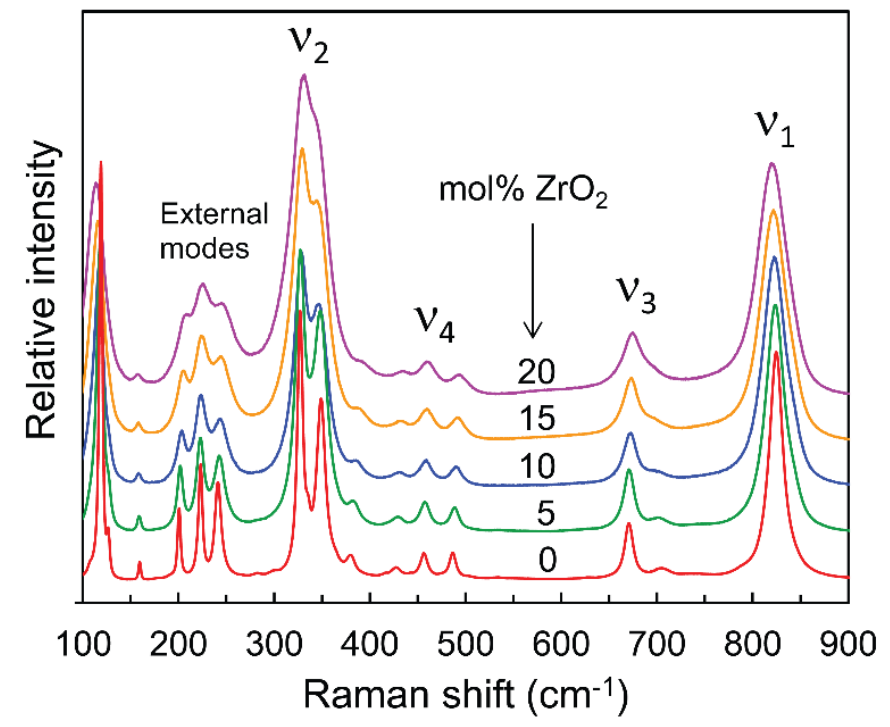

Fig. 4. Raman spectra of the zirconia-stabilized $\mathrm{YTaO}_{4}$. The spectra from the materials with different zirconia contents are shown for comparison. No substantive changes in the spectra with zirconia concentration are evident indicating that the crystal structure did not change with zirconia alloying. 

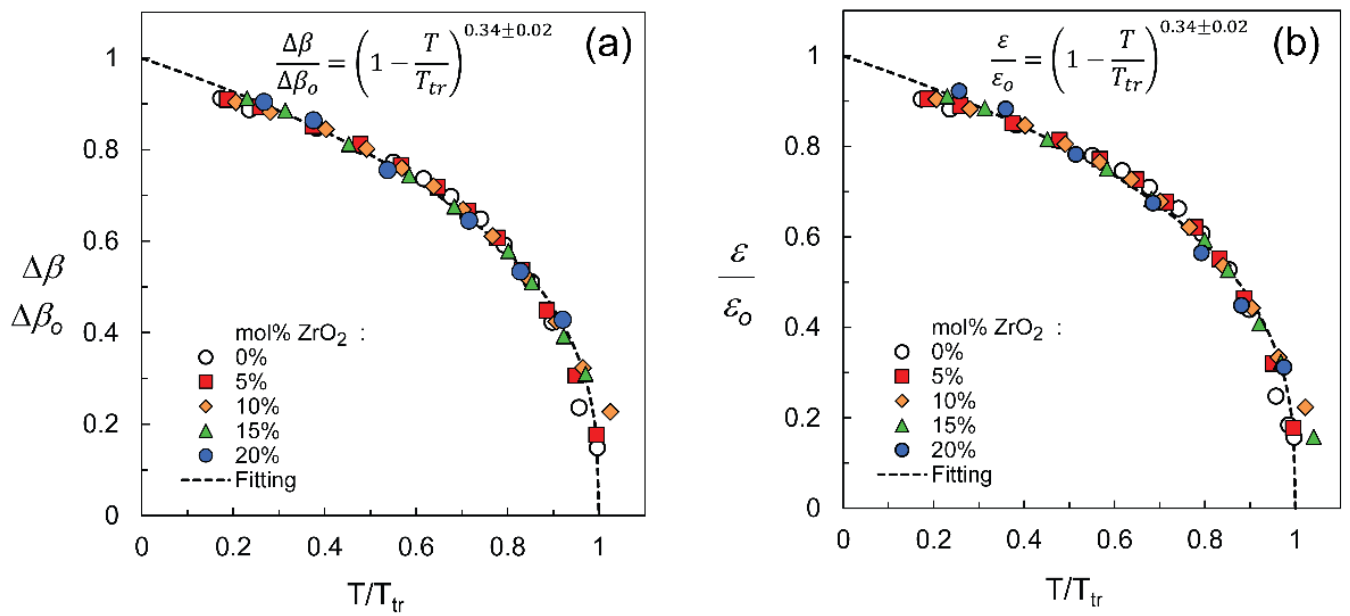

Fig. 5. (a) Normalized monoclinic angles $\left(\Delta \beta / \Delta \beta_{o}\right)$ and (b) Normalized spontaneous strains $\left(\varepsilon / \varepsilon_{o}\right)$, both plotted as a function of normalized transformation temperature, $\left(\mathrm{T} / \mathrm{T}_{\mathrm{tr}}\right)$. Note that both sets of data closely fit to a mean field model for the transformation and suggest that it is a continuous, displacive transformation. The error bars are smaller than the symbol size. 


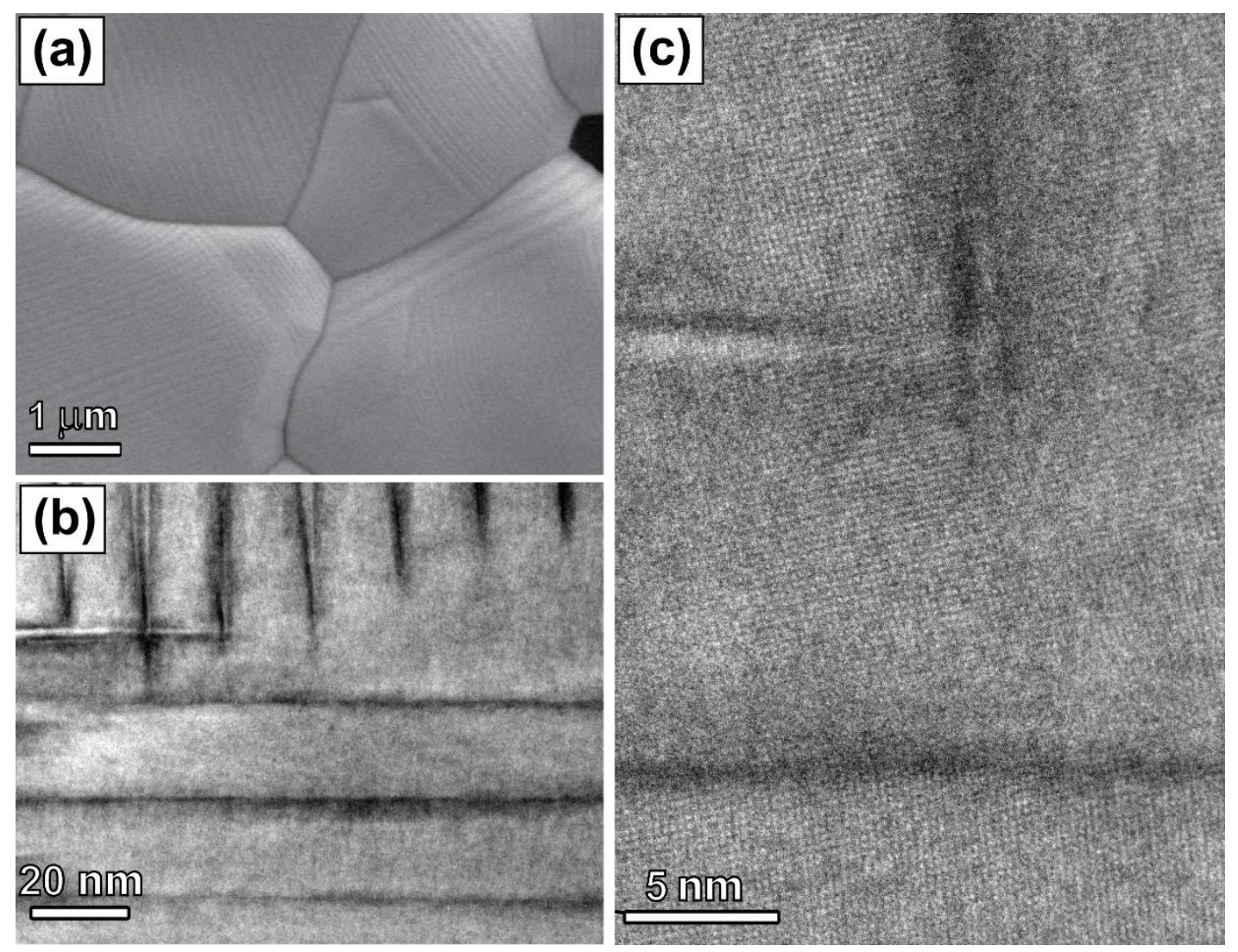

Fig. 6. (a) SEM image of $\mathrm{YTaO}_{4}$, showing twin domains on the surface of the grains. (b) TEM image of the twin domains showing the intersection of perpendicular domains within one grain. This intersection is magnified in HRTEM image (c), which also clearly indicates the presence of horizontal twin domain boundary. 